\title{
Oil Speculation: The Impact On Prices, Inflation, Interest Rates And The Economy
}

Emmanuel I.S. Ajuzie, Lincoln University, USA Roberto M. Ike, Lincoln University, USA

\begin{abstract}
The vector autoregression process is used to estimate a reformulated model of the equation of exchange developed from the quantity theory of money. In describing the effect of oil speculation, represented by spot oil price, on general price level and the overall economy, new variables are incorporated to take into account current global economic conditions and realities. A variable, which was introduced in Ajuzie et al, 2008 paper, import of goods and services, is included and impulse-response function is used to forecast future economy and determine policy scenarios. Results show that an increase in spot oil price last period has a highly statistically significant positive effect on CPI inflation. This effect is strong enough to eliminate the negative significant impact of import of goods and services on CPI inflation found in the paper of May 2008. Based on this finding, it is highly recommended that oil speculation should be discouraged and trade relations be bases purely on the principles of comparative advantage.
\end{abstract}

Keywords: Oil speculation, inflation, impulse-response function, interest rate, inflationary pressure, equation of exchange, quantity theory of money, vector-autoregression, consumer price index, import, growth rate, spot oil price, goods and services, general price level, and comparative advantage

\section{INTRODUCTION}

n a previous paper, Ajuzie et al, (2008), we primarily examined the impact of the importation of goods and services on consumer price index (CPI) inflation and consequently on the rate of interest. We proposed some policy strategies to return the economy on a healthy path. One of those recommendations dealt with the need to, as much as is possible, stop or reduce oil speculation, which was seen as a buster of economic growth. In order to arrive at that conclusion, a more modern theoretical formulation of the equation of exchange was developed. It incorporated imports of goods and services and oil as new variables that impact the economy and inflationary pressures in very significant ways.

This study borrows the formulation in that paper to make the case for the pressing need to examine in-depth the consequences of oil speculation on the economy. In a news article published online by Associated Press Monday, June 20, 2008, it was reported that the Congress was holding listening sessions to determine whether or not oil speculation has any impact on the economy. Most of the panelists agreed that, somehow, oil speculation has a negative effect on the economy.

This paper employs relevant data to determine the statistical nature of that effect on the economy. Again, we can explain inflation using the quantity theory of money (QTM). The theory emphasizes that money supply is the principal determinant of nominal gross domestic product (GDP). The QTM can be explained with reference to the equation of exchange and shows the relationship among money supply, income velocity of money, GDP deflator, and real GDP. This theoretical framework is taken from Ajuzie, et al, 2008 paper referred to above.

\section{THE THEORETICAL MODEL}

The reformulated equation of exchange incorporates new variables, which impact United States economy on the backdrop of the global economy of the $21^{\text {st }}$ century. These new variables of interest incorporated in the May 
2008 paper and led to the expansion of the original equation of exchange are imports of goods and services (IMP) and oil import (OIL). The first equation could be represented as follows:

$d M 2 / M 2+d V / V=d C P I / C P I+d G D P / G D P+d I M P / I M P+d O I L / O I L$

where $d M 2 / M 2$ represents the growth rate of the money supply, $d V / V$ the growth rate of the velocity of money, $d C P I / C P I$ the growth rate of consumer price index, $d G D P / G D P$ the growth rate of gross domestic product, $d I M P / I M P$ is the growth rate of imports of goods and services, and $d O I L / O I L$ is the growth rate of oil import. We use M2 for our money supply measure. Imports are regarded as the value of all goods and services except oil in one-month period. $d O I L / O I L$ represents the growth rate of oil imports in one-month period. We replace $P$, the GDP deflator, with $C P I$ inflation since it includes import prices and measures inflationary pressures before they reach the consumer. Therefore, $d C P I / C P I$ becomes the growth rate of $C P I$ inflation. By holding the velocity of money constant, equation (1) becomes:

$d M 2 / M 2=d C P I / C P I+d G D P / G D P+d I M P / I M P+d O I L / O I L$

Equation (2) states that the growth rate of money supply equals the growth rate of CPI inflation plus output growth rate plus the growth rate of imports of all goods and services except oil plus the growth rate of oil import. Rearranging terms and solving for the growth rate of CPI inflation we have:

$d C P I / C P I=d M 2 / M 2-d G D P / G D P-d I M P / I M P-d O I L / O I L$

Equation (3) states that the growth rate of CPI inflation equals the growth rate of money supply minus output growth rate minus the growth rate of all imports of goods and services, except oil, minus the growth rate of oil import. In order to examine the impact of oil speculation on inflation, we include that variable in the reformulated equation. Equation (3) becomes:

$d C P I / C P I=d M 2 / M 2-d G D P / G D P-d I M P / I M P-d O I L / O I L-d S T P / S T P$

where $d S T P / S T P$ is the growth rate of spot oil price, which is a measure of oil speculation at the Mercantile Exchange House. The assumption is that speculation in spot oil prices leads to acceleration of CPI inflation. These price increases are easily transferred to the consumer and quickly spread through the financial system, leading to serious market distortions with unintended dire consequences on the poor, those on low fixed income, retirees, and farmers.

With this formulation, we would investigate the effect of changes in the value of oil import, gross domestic product, money supply, import of goods and services, and spot oil price on the rate of CPI inflation. The focus would primarily be on spot oil price, STP.

\section{THE EMPIRICAL MODEL}

In order to primarily demonstrate the effect of oil speculation on inflation, we propose empirical application following Ajuzie, et al (2008). The dynamic model of the macro-economy used is the Vector Autoregressive (VAR) estimation procedure. It involves running three-step analyses, namely:

- $\quad$ Test the stationarity for each variable

- $\quad$ Finding that variables are stationary, use the VAR model for estimation

- $\quad$ Based on the VAR estimation, perform the impulse-response function for forecast and policy analysis.

The mathematical representation of the VAR is:

$y_{t}=A_{1} y_{t-1}+\ldots+A_{p} y_{t-p}+B x_{t}+\in t$

where $y_{t}=\left(C P I\right.$, GDP, IMP, M2, OIL, STP) is a vector of endogenous variables, the $x_{t}$ is a vector of exogenous variables (we let a constant be the only exogenous variable in our model). The $A_{1}, A_{2}, \ldots, A_{p}$ are matrices of coefficients to be estimated, and $\varepsilon_{\mathrm{t}}$ is a vector of innovations that may be contemporaneously correlated but are 
uncorrelated with their own lagged values and uncorrelated with all of the right-hand side variables, and the error term. The Akaike Information Criterion (AIC) was used to specify the optimal lags as 2 in the VAR system.

Based on Ajuzie, et al (2008), the impulse-response function is used for forecast and policy discussion. We use the generalized impulse-response function (Pesaran, M. H. and Shin, Y., 1997) which does not depend on the Cholesky order selection as the simple impulse-response generation. A shock to the $i^{\text {th }}$ variable not only directly affects the $\mathrm{i}^{\text {th }}$ variable but is also transmitted to all of the other endogenous variables through the dynamic (lag) structure of the VAR. An impulse response function traces the effect of a one-time shock to one of the innovations, $\varepsilon_{t}$, on current and future values of the endogenous variables.

The impulse-response function is plotted in 12-lags/months with 2-standard deviations. For example, the response of CPI to OIL implies that a shock in OIL has an immediate positive though insignificant effect of up to $0.0002 \%$ on overall consumer prices. The impact declines and reaches a slightly negative effect in 2 to 3 periods, then the effect dies out and the consumer price goes back to equilibrium. follows:

The stationarity was performed using the Augmented Dicky-Fuller (ADF) model, which can be specified as

$$
\Delta y_{t}=\alpha y_{t-1}+\delta x_{t}{ }^{\prime}+\beta_{1} \Delta y_{t-1}+\beta_{2} \Delta y_{t-2}+\ldots+\beta_{p} \Delta y_{t-p}+v_{t}
$$

The null hypothesis is Ho: $\alpha=1$, and the $y$ denotes each variable. All tests reject the unit-root hypothesis at $1 \%$ significance level, so we confirm that all variables are stationary and a VAR can be specified and used to run the regression analysis.

\section{DATA SOURCE:}

Secondary data were collected on six variables, namely consumer price index (CPI inflation), Money supply (M2), real gross domestic product (GDP), imports of goods and services (IMP), value of crude oil imports (OIL), and speculative spot oil price (STP). Monthly data were collected on these variables from January 1993 through June 2008, yielding a total of 186 observations. The quarterly GDP data were extrapolated to monthly data. Then the data on the six variables were converted to growth rates for purposes of estimation, resulting in a reduction in the number of observations to 185 . Sources of the secondary data are the Bureau of Economic Analysis (BEA), Bureau of Labor Statistics, and US Bureau of the Census.

\section{RESULTS}

Table 1 below is the augmented Dickey -Fuller (ADF) Test. As stated above, the tests reject the null-root hypothesis at $1 \%$ significance level. This led to the confirmation that all variables are stationary and that VAR could be specified.

Table 1: Augmented Dickey-Fuller Test (The Null Hypothesis: Has a Unit Root)

\begin{tabular}{|l|l|l|l|l|}
\hline Variable & T-statistics & & \\
\hline CPI & -10.46812 & $* * *$ & & \\
\hline M2 & -9.24263 & $* * *$ & & \\
\hline GDP & -11.39255 & $* * *$ & & \\
\hline IMP & -4.692783 & $* * *$ & & \\
\hline OIL & $-15.15354 * * *$ & & \\
\hline STP & $-11.91868 * * *$ & & \\
\hline Notes: The $* * *$ denotes the significance at $1 \%$ level. The critical values of ADF test statistics & \\
\hline are -3.47, -2.88, and -2.58 at $1 \%, 5 \%$, and $10 \%$ significant levels respectively. & \\
\hline
\end{tabular}


Table 2: Vector Autoregression Es timates

\begin{tabular}{|c|c|c|c|c|c|c|c|c|c|c|c|c|}
\hline & CPI & & M2 & & GDP & & IMP & & OIL & & STP & \\
\hline \multirow[t]{3}{*}{ CPI(-1) } & 0.122895 & & -0.17385 & & -0.028599 & & -0.22733 & & -4.108774 & & -10.5911 & $* * *$ \\
\hline & $(0.08660)$ & & (0.12563) & & (0.11941) & & $(0.63639)$ & & $(3.75492)$ & & $(2.96678)$ & \\
\hline & [ 1.41903] & & {$[-1.38382]$} & & [-0.23949] & & {$[-0.35722]$} & & {$[-1.09424]$} & & [-3.56988] & \\
\hline \multirow[t]{3}{*}{ CPI(-2) } & -0.23145 & $* * *$ & -0.10812 & & -0.170907 & & 0.788337 & & -2.633595 & & -2.83557 & \\
\hline & (0.08474) & & (0.12292) & & $(0.11684)$ & & $(0.62265)$ & & (3.67386) & & (2.90274) & \\
\hline & {$[-2.73141]$} & & {$[-0.87963]$} & & {$[-1.46280]$} & & [ 1.26609] & & {$[-0.71685]$} & & [-0.97686] & \\
\hline \multirow[t]{3}{*}{ M2(-1) } & -0.0617 & & 0.29004 & $* * *$ & 0.020389 & & -0.58131 & & -0.374354 & & -1.02967 & \\
\hline & $(0.05265)$ & & (0.07637) & & $(0.07259)$ & & $(0.38687)$ & & $(2.28265)$ & & (1.80354) & \\
\hline & [-1.17188] & & [ 3.79772] & & [ 0.28088$]$ & & {$[-1.50261]$} & & {$[-0.16400]$} & & {$[-0.57092]$} & \\
\hline \multirow[t]{3}{*}{ M2(-2) } & 0.033228 & & 0.14298 & $*$ & 0.036846 & & -0.4565 & & 1.780301 & & 1.537077 & \\
\hline & $(0.05224)$ & & (0.07578) & & $(0.07203)$ & & $(0.38387)$ & & (2.26496) & & $(1.78956)$ & \\
\hline & [ 0.63605$]$ & & [ 1.88674] & & [ 0.51154$]$ & & {$[-1.18919]$} & & [ 0.78602$]$ & & [ 0.85891$]$ & \\
\hline \multirow[t]{3}{*}{ GDP(-1) } & -0.00898 & & -0.0872 & & 0.181014 & $* *$ & 0.743893 & $*$ & -0.224064 & & -2.79537 & \\
\hline & (0.05444) & & (0.07897) & & $(0.07506)$ & & (0.40003) & & $(2.36032)$ & & $(1.86491)$ & \\
\hline & [-0.16489] & & {$[-1.10424]$} & & [ 2.41151] & & [ 1.85958] & & {$[-0.09493]$} & & [-1.49893] & \\
\hline \multirow[t]{3}{*}{ GDP(-2) } & -0.03506 & & -0.25533 & $* * *$ & -0.084293 & & 0.278519 & & 0.269908 & & 2.088316 & \\
\hline & (0.05531) & & $(0.08023)$ & & $(0.07626)$ & & $(0.40642)$ & & $(2.39801)$ & & (1.89468) & \\
\hline & {$[-0.63397]$} & & {$[-3.18252]$} & & {$[-1.10532]$} & & {$[0.68530]$} & & [ 0.11256$]$ & & [ 1.10220$]$ & \\
\hline \multirow[t]{3}{*}{$\operatorname{IMP}(-1)$} & -0.00427 & & 0.01611 & & 0.011846 & & -0.26776 & $* * *$ & 0.419643 & & 0.731028 & $* *$ \\
\hline & $(0.01053)$ & & $(0.01528)$ & & $(0.01452)$ & & $(0.07740)$ & & $(0.45667)$ & & $(0.36081)$ & \\
\hline & [-0.40507] & & [ 1.05448] & & [ 0.81568$]$ & & [-3.45963] & & [ 0.91893$]$ & & [ 2.02605] & \\
\hline \multirow[t]{3}{*}{$\operatorname{IMP}(-2)$} & 0.007889 & & -0.00238 & & 0.033411 & $* *$ & -0.15478 & $* *$ & 0.418369 & & 0.664262 & $*$ \\
\hline & (0.01050) & & $(0.01523)$ & & $(0.01448)$ & & (0.07717) & & $(0.45532)$ & & (0.35975) & \\
\hline & [ 0.75121$]$ & & [-0.15605] & & [ 2.30741] & & {$[-2.00576]$} & & [ 0.91884$]$ & & [ 1.84643] & \\
\hline \multirow[t]{3}{*}{ OIL(-1) } & 0.000209 & & 0.00121 & & 0.003904 & & -0.02497 & $*$ & -0.542925 & $* * *$ & -0.12891 & $* *$ \\
\hline & (0.00189) & & $(0.00274)$ & & $(0.00261)$ & & $(0.01390)$ & & (0.08199) & & $(0.06478)$ & \\
\hline & [ 0.11063$]$ & & [ 0.44015$]$ & & [ 1.49717] & & {$[-1.79708]$} & & {$[-6.62185]$} & & [-1.98997] & \\
\hline \multirow[t]{3}{*}{ OIL(-2) } & 0.000515 & & 0.00126 & & 0.000782 & & -0.01498 & & -0.144757 & $*$ & -0.00778 & \\
\hline & (0.00174) & & $(0.00253)$ & & $(0.00240)$ & & $(0.01280)$ & & $(0.07552)$ & & (0.05967) & \\
\hline & [ 0.29581$]$ & & [ 0.49737$]$ & & [ 0.32547$]$ & & {$[-1.17018]$} & & {$[-1.91685]$} & & {$[-0.13034]$} & \\
\hline \multirow[t]{3}{*}{ STP(-1) } & 0.011178 & $* * *$ & -0.00115 & & -0.001652 & & 0.090087 & $* * *$ & 0.915531 & $* * *$ & 0.273499 & $* * *$ \\
\hline & $(0.00271)$ & & (0.00393) & & (0.00374) & & (0.01991) & & $(0.11747)$ & & $(0.09282)$ & \\
\hline & [ 4.12553] & & [-0.29195] & & {$[-0.44225]$} & & [ 4.52473] & & [ 7.79342] & & [ 2.94663] & \\
\hline \multirow[t]{3}{*}{$\operatorname{STP}(-2)$} & 0.001491 & & -0.00091 & & -0.004527 & & 0.036833 & $*$ & 0.60585 & $* * *$ & 0.134636 & \\
\hline & $(0.00301)$ & & $(0.00436)$ & & $(0.00415)$ & & (0.02209) & & $(0.13034)$ & & (0.10298) & \\
\hline & [ 0.49600$]$ & & [-0.20941] & & {$[-1.09222]$} & & [ 1.66735] & & [ 4.64813] & & [ 1.30734] & \\
\hline \multirow[t]{3}{*}{$\mathrm{C}$} & 0.002554 & $* * *$ & 0.00387 & $* * *$ & 0.002061 & $* * *$ & 0.010441 & $* * *$ & 0.014414 & & 0.02927 & $*$ \\
\hline & $(0.00045)$ & & $(0.00065)$ & & $(0.00061)$ & & $(0.00328)$ & & (0.01934) & & $(0.01528)$ & \\
\hline & [ 5.72622] & & [ 5.98147] & & [ 3.35122] & & [ 3.18581] & & [ 0.74539$]$ & & [ 1.91568$]$ & \\
\hline R-squared & 0.254813 & & 0.2208 & & 0.090445 & & 0.210516 & & 0.371555 & & 0.149127 & \\
\hline Adj. R-squared & 0.20221 & & 0.16579 & & 0.02624 & & 0.15479 & & 0.32719 & & 0.08907 & \\
\hline \multicolumn{2}{|c|}{ Akaike information criterion } & & -37.4284 & & & & & & & & & \\
\hline
\end{tabular}

Notes: The $* * *, * *$, and $*$ denote the significance at the $1 \%, 5 \%$, and $10 \%$ levels respectively. The (.) is the standard error and the [.] is the corresponding t-statistic 
Table 2 represents the VAR estimation, which uses the Akaike Information Criterion (AIC) to specify the optimal lags as 2 in the VAR system. The (.) represents the standard error and the [.] denotes the test-statistics. For the sake of space within the Table, the $p$-values for determining the significance levels of the estimates could not be displayed.

The VAR regression estimate is based on past information. It is a 5-GLS regression systematically, so each column is one corresponding variable/regression estimate. For example, the estimate of CPI is:

$\mathrm{CPI}_{\mathrm{t}}=0.12 * \mathrm{CPI}_{\mathrm{t}-1}-0.23 * \mathrm{CPI}_{\mathrm{t}-2}-0.06 * \mathrm{M}_{\mathrm{t}-1}+0.03 * \mathrm{M}_{\mathrm{t}-2}+0.01 * \mathrm{GDP}_{\mathrm{t}-1}-0.04 * \mathrm{GDP}_{\mathrm{t}-2}-0.004 * \mathrm{IMP}_{\mathrm{t}-1}+0.01 * \mathrm{IMP}_{\mathrm{t}-}$ ${ }_{2}+0.0002 * \mathrm{OIL}_{\mathrm{t}-1}-0.0005 * \mathrm{OIL}_{\mathrm{t}-2}+0.01 * \mathrm{STP}_{\mathrm{t}-1}+0.001 * \mathrm{STP}_{\mathrm{t}-2}$

For instance, at a $1 \%$ level of significance, we can say that an increase in the spot oil price, STP, in the last period has a highly statistically significant positive effect of 0.011 , on CPI inflation. It still has a positive effect, 0.001 , into the second period though no longer statistically significant.

Other variables could be calculated similarly. For example, the estimate of M2 is as follows:

$\mathrm{M} 2_{\mathrm{t}}=-0.17 * \mathrm{CPI}_{\mathrm{t}-1}-0.11 * \mathrm{CPI}_{\mathrm{t}-2}+0.29 * \mathrm{M} 2_{\mathrm{t}-1}+0.14 * \mathrm{M} 2_{\mathrm{t}-2}-0.09 * \mathrm{GDP}_{\mathrm{t}-1}-0.26 * \mathrm{GDP}_{\mathrm{t}-2}+0.02 * \mathrm{IMP}_{\mathrm{t}-1}-0.002 * \mathrm{IMP}_{\mathrm{t}-}$ ${ }_{2}+0.001 * \mathrm{OIL}_{\mathrm{t}-1}-0.001 * \mathrm{OIL}_{\mathrm{t}-2-0}-0.002 * \mathrm{STP}_{\mathrm{t}-1}-0.0009 * \mathrm{STP}_{\mathrm{t}-2}$

\section{THE IMPULSE RESPONSE FUNCTION}

We present the model-generated impulse responses of the variables, especially of CPI to spot oil price (STP). The impulse-response function is a forecast of the future economy based on all current information. For instance, an unexpected increase in the spot price of oil in time $t=0$ has an immediately positive effect on CPI inflation at time $t=0$ and $t=1$. Over time, $t=2$ and 3 , the effect is gradually decreased and the escalating effect at time $\mathrm{t}=0$ on CPI inflation disappears at time $\mathrm{t}=4$.

In Figure 1, we show CPI response to STP. It would be reasonable to suggest that a sudden increase in the speculative spot oil price significantly increases the CPI inflation immediately. The increase continues through the first and second periods but this immediate effect will decrease and die off with the real fact reorganization or economic stabilization over time, approximately within three to four periods. The disturbing observation with oil speculation, especially between May and September 2008, was that the initial STP shock was not given time to die off before other more intense shocks were introduced in quick successions. This resulted in the pressure for CPI inflation to escalate continuously and ripple throughout the economy, exacerbating recessionary imperatives. The data used in this study include the highest STP of \$147.45, which was reached in a trading day in mid-July 2008.

\section{Response of CPI to STP}

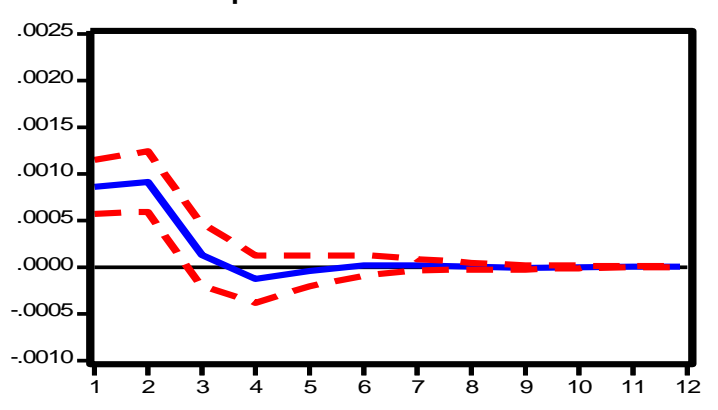

Figure 1. Response of CPI to STP 
The economy has been quite resilient and inflation has not escalated as would have been the case if imported cheaper goods and services were not offsetting potential rises in the price of domestic output. It would be interesting to briefly and closely compare this and the result in Ajuzie, et al, 2008 with regard to the behavior of IMP, CPI, and STP. Figure 1 shows the inclusion of STP. In the May paper, which excluded STP, IMP had a statistically significant negative impact on CPI inflation. In other words, IMP reduced the growth rate of CPI inflation significantly. In this analysis IMP, Figure 2, still has negative impact on CPI inflation but only in the first period and it is conspicuously statistically insignificant. We can make the case that since the only thing that changed in the two models is the inclusion of STP in this formulation, the non-statistical significance of IMP in this model is attributable to the continuous offsetting influence of STP. It significantly counter-balances the effect of IMP in holding off inflationary pressures. This means that as speculatory prices of oil escalate and reach gasoline pumps, we have constant inflationary pressures. However, the force would be somewhat dampened by IMP in the first period even though it is statistically insignificant.

A close examination and comparison of Figures 1 and 2, gives much weight to this argument. The shock from STP on CPI in Figure 1 is almost twice the shock from IMP in Figure 2. Again, in Ajuzie et al, 2008, we found that IMP reduced the growth rate of CPI inflation. Oil speculation, because it eliminates the significance of the power of IMP to reduce the growth rate of CPI inflation, threatens to put us back into constantly worrying about inflationary pressures in the economy, which mitigating policy strategies to adopt, and when to adopt them in order to attain full employment, stable prices, and low inflation; the main goals of the resilient economy of the United States.

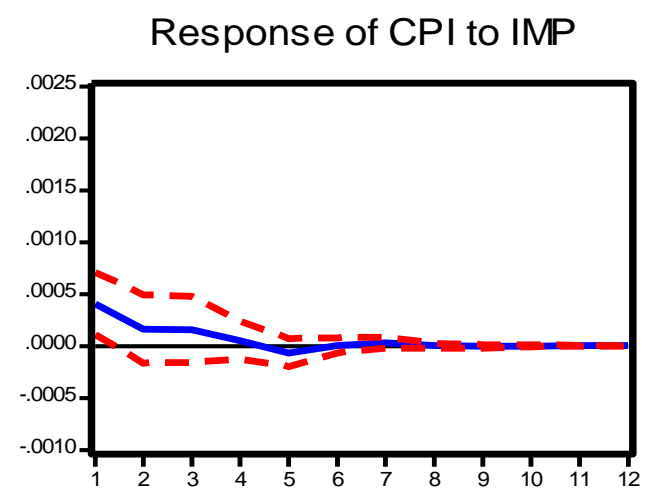

Figure 2: Response of CPI to IMP

The impact of M2 and GDP on CPI inflation is insignificant, and the effect dies off quickly. The response of CPI to OIL implies that a shock in crude oil prices has an insignificant immediate positive effect of up to $0.0002 \%$ on overall consumer prices in the first period, Figure 3. With a response of .0005\% in the second period, it is still insignificant. The impact steadily declines and reaches a slightly negative effect in the third period, then the effect dies off and the consumer price goes back to equilibrium.

The increase in the price of crude oil (OIL) results from an increase in the speculatory price of oil. In other words, the price of crude oil at the source of production is determined by, or derived from, the STP. The insignificance of the impact of GDP on CPI inflation is symptomatic of the fact that as aggregate domestic demand outpaces aggregate domestic supply, the staggering importation of cheap goods and services is used to augment domestic supply deficiency, resulting in reduced incentive to bid up the price of domestic output and leading to reduction in the escalation of inflation. This is evidenced by the skyrocketing U.S. trade deficit and tends to make a strong case for open economy and trade among nations strictly based on the principles of comparative advantage. 


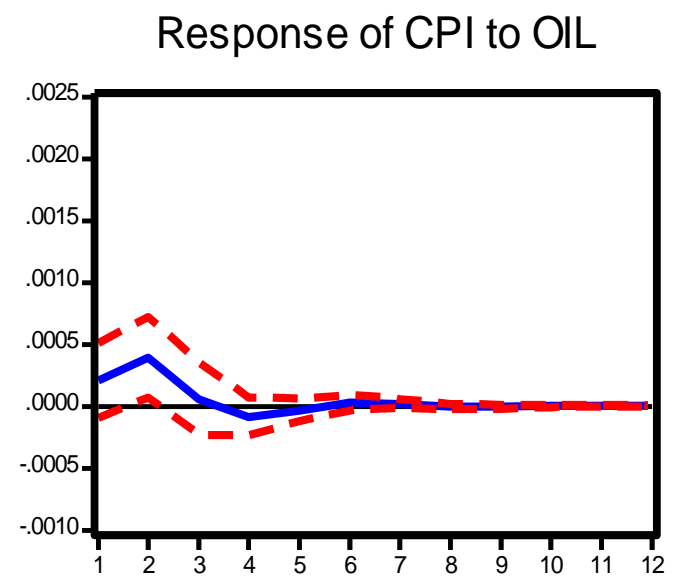

Figure 3: Response of CPI to OIL

\section{POLICY IMPLICATION}

1. Oil speculation should be discouraged as much as possible. This is one of the causes of the present financial crisis. The rise in STP led to escalating general price level and the demise of some businesses as they could not cope with increased energy costs. The decrease in STP in the previous few months led to a great loss of assets by big investors who waged their fiscal hopes on the fast rising STP.

2. Interest rate should be kept low and monitored using equation (15) in Ajuzie et al, May 2008 as a benchmark. Under this principle, interest rate could continue to go down.

3. Commercial banks should be pressed to lower their business and consumer lending rates to reflect the reduction in Federal funds and discount rates, even if there is no direct link between the rates. It would loosen credit and spur investment borrowing, job creation, and home purchase or refinancing.

4. As we gradually work toward the development of solar and wind energy, we should immediately rely mostly on the use of technology to get us out of the dependence on foreign oil. For example, some new catalic converter could dramatically increase the fuel efficiency of automobiles. This is capable of saving millions of barrels of oil a day when half of the cars in the nation are converted.

5. If we follow the principles of comparative advantage in our trade relations, imports would continue to reduce the growth rate of inflation and there would be no fear of deflation in the economy as some have broached.

\section{SUMMARY AND CONCLUSION}

In Ajuzie, et al, 2008, several recommendations were put forward to assist in reducing the financial crisis the nation's economy is facing. One of them dealt with the need to regulate or reduce the speculation in crude oil. That conclusion was reached by examining the impact of oil import on general price level. We found that the effect was positive in the first period and negative in the second period. Both effects were statistically insignificant and disappeared by the third period.

In this paper, crude oil import price is not a factor as it becomes even more statistically insignificant in its effect on CPI inflation. The negative second period estimate in the first analysis turned positive here, though insignificant. On the other hand, the new variable STP, which is a measure of oil speculation, is positive and highly statistically significant at the one percent level of significance. This implies that in the first period oil speculatory price shock raises CPI inflation by 0.01 percentage point. At 0.001 percentage point, it remains positive in the second period, though no longer statistically significant. The effect does not die down until about the fourth period. 
We therefore conclude that it is not really crude oil prices that drive the price of gasoline at the pump but speculatory prices of oil. In other words, crude oil prices react to, or are derived from, STP. The data used in this study include the highest STP in mid-July 2008, which was recorded at $\$ 147.45$ per barrel.

What does it all mean? We can infer that the skyrocketing increases in the speculatory prices of oil, STP, were driven not necessarily by the forces of supply and demand but by other economic concerns and aspirations of global capitalistic societies, with everyone pursuing his/her own self interest. The implication is that the unwarranted increases in the STP led to soaring energy costs, which in turn resulted in high cost of doing business, the bankruptcy of businesses, declining output, lay off of workers, reversal of economic growth, and great uncertainties in financial markets. As STP declines from its highest level in July 2008, many large investors who waged their hopes on a continuously soaring STP lost substantial amount of assets, resulting in financial meltdown, recession, and "bailouts" to stay afloat.

With the ballooning prices of oil, some oil producing countries used the windfall to invest in noneconomicgrowth sectors instead of capital accumulation, which would enable them to increase future production and enhance economic growth. As the price of oil falls, one can only speculate what the future would be for all those investments in nonproductive ventures. We are not implying here that oil speculation is the only culprit in the mess we are in now, but its role is quite significant and any strategy to reduce that effect would be a step in the right direction.

The need to operate in commodity markets to maintain steady purchases and delivery processes of goods and services, especially oil, cannot be over emphasized. The nation's economic health demands that we have uninterrupted production and supply of energy and the commodity market in crude oil assures us of a continuous flow of the resource. However, because of its extraordinary ability to positively impact the general price level and lead to inflation and all the attendant economic ills, we recommend that oil should not be the target of intense speculation. What has happened in the past year or so is that our capitalistic drive saw the apparent inelastic demand for oil by nations and decided to accrue inordinate amount of profits regardless of its effect on global economies.

As this paper is being put together, oil speculation is gradually easing and crude oil prices are declining. This is being reflected slowly at gasoline pumps. Consumers are going to use the savings from gasoline to purchase other goods and services, a process that would increase production and begin to spur economic growth, all things being equal. Import of goods and services would resume its power of ameliorating inflationary pressures in the economy. Interest rate would react by remaining low; a situation that would improve business borrowing for investment purposes, consumer borrowing to refinance or buy new homes, and by farmers to purchase farm equipment.

The loosening of credit would be achieved by lowering consumer lending rate to reflect the low federal funds and Federal discount rates even if they are not directly related. At the time this paper was presented at a conference in March 2009, there was a fear of deflation. This study shows that that fear was speculatory, not founded and evidential. At the time, and before the present increase in oil speculation, we were observing import of goods and services resuming its effect on reducing the growth rate of inflation, and thus the prices of goods and services. If we do not check this current pressure on oil speculation, we will witness stalling economic and jobless recovery.

\section{AUTHOR INFORMATION}

Emmanuel I. S. Ajuzie, Lincoln University of Missouri, Jefferson City, MO 65102. He is an Associate Professor, working as Research and Extension Economist and teaches Economics and Environmental and Natural Resource Economics. He has authored and co-authored book chapters and articles and abstracts in refereed journals, and conference proceedings in various areas of Economics and Agricultural Economics.

Roberto M Ike, Head of the Department of Economics and Business, Lincoln University of Missouri, Jefferson City, MO 65102. Dr. Ike teaches courses in Business Administration and Organizational Behavior, and has authored and co-authored a book and several articles in refereed journals and conference proceedings. 


\section{REFERENCES}

1. Ajuzie, Emmanuel I.S., Felix M. Edoho, Wensheng Kang, Matthew N. Uwakonye, and Ghebre Y. Keleta. (2008) "Import Response and Inflationary Pressures in the New Economy: The Quantity Theory of Money Revisited." Journal of Business and Economic Research, Vol. 6, No. 5, May, pp 125-139.

2. Ajuzie, Emmanuel I.S. (2000). "Interest Rates and Inflationary Pressures, Real or Imagined: The Reality of Our Time and Implications for Farmers." Lincoln University Faculty Working Paper 01-07.

3. Antoine, Murphey. (1983). Richard Cantillon, Banker and Economist, Journal of Libertarian Studies.

4. Aversa, Jeannine. (2007). Bernanke Still Optimistic About Economy, Associated Press Economics Writer. February 14, 2007.

5. Barton, Philip. Import and Inflation. philipbarton@bigpond.com. July 11, 2006

6. Bureau of Economic Analysis for data

7. Bureau of Labor Statistic for data

8. Fisher, Irvin. (1911) Purchasing Power of Money: Its Determination and Relation to Credit, Interest and Crises, American Economic Review.

9. Fisher, Irvin, (1911). The Equation of Exchange, 1896-1910, American Economic Review.

10. Fisher, Irvin, (1911) Recent Changes in Price Levels and Their Causes, American Economic Review Discussion.

11. Fisher, Irvin, (1913). The Equation of Exchange for 1912, and Forecast, American Economic Review.

12. Friedman, Milton and Anna J. Schwartz (1965). The Great Contraction 1929-1933, Princeton: Princeton University Press.

13. Gordon, Robert J. 1977. "Can the Inflation of the 1970s Be Explained?" Brookings Papers on Economic Activity, vol. 8, pp. 253-77.

14. Heakal, Reem. (January 7, 2005). What Is the Quantity Theory of Money? Investopedia.

15. Keynes, John Maynard. (1936). General Theory of Employment, Interest, and Money.

16. Locke, John. (1692). Consequences of the Lowering of Interest and Raising the Value of Money.

17. Moomaw, Ronald L. and Kent W. Olson. (2007). Economics and Contemporary Issues. $7^{\text {th }}$ ed. Thomson, South-western.

18. Staiger, Douglas, James H. Stock, and Mark W. Watson. (1997). "The NAIRU, Unemployment, and Monetary Policy." Journal of Economic Perspectives, vol. 11, no. 1, pp. 33-50.

19. Tootell, Geoffrey M.B. 1998. "Globalization and U.S. inflation.” Federal Reserve Bank of Boston, New England Economic Review, July.

20. Tootell, Geoffrey M.B. (1994). "Restructuring, the NAIRU, and the Phillips Curve." Federal Reserve Bank of Boston, New England Economic Review, September/October, pp. 31-44. 


\section{NOTES}

